\title{
Treatment outcomes for adult patients with localized osteosarcoma treated with chemotherapy without methotrexate at a public hospital in Brazil
}

Marilia Polo Minguete-e-Silva', Renata Rodrigues da Cunha Colombo Bonadio', Gustavo Matos', Diego de Araújo Toloi', Rodrigo Ramella Munhoz', Mirella Nardo', Daniel Rebolledo', Luiz Filipe Marques Correa ${ }^{1}$, Andre Mathias Baptista ${ }^{1}$, Caroline Chaul de Lima Barbosa Zampieri ${ }^{1}$, Olavo Feher ${ }^{1}$, Veridiana Pires de Camargo ${ }^{1}$

\begin{abstract}
Introduction: Standard treatment for pediatric patients with localized osteosarcoma includes high-dose methotrexate (HDMTX), and cure rates greater than $60 \%$ are observed. However, in adult patients, the toxicity profile limits the use of HDMTX and the drug is usually excluded from chemotherapy protocols for this group. We aimed to evaluate the outcomes of adult patients with localized osteosarcoma treated with chemotherapy without methotrexate. Methods: In this retrospective cohort, we evaluated adult patients with high-grade osteosarcoma who received chemotherapy treatment without methotrexate in a reference cancer center from 2007 to 2018. Outcomes analyzed were recurrence-free survival (RFS), overall survival (OS), and prognostic factors associated with overall survival. Results: A total of 48 patients had localized disease and received treatment with chemotherapy without methotrexate. The majority of them received chemotherapy with a combination of cisplatin and doxorubicin ( $n=42,87.5 \%)$. Median age was 27 years (range 16.8-66.7). With a median follow-up of 29.2 months, median RFS was 29.9 months. Median OS was not reached. 5-year RFS and OS rates were 35.1\% (95\% Cl: 20.3-50.2\%) and $71.6 \%$ (95\% Cl: 52.3-84.2\%), respectively. Patients who received cumulative doses of doxorubicin $\geq 375 \mathrm{mg} / \mathrm{m} 2$ had better OS than those who received lower doses (HR 0.26, 95\% Cl: $0.07-0.94, p=0.041)$. Similarly, patients who received $\geq 6$ cycles of neoadjuvant/adjuvant cisplatin tended to have better OS than those who received $<6$ cycles (HR 0.30, 95\% Cl: 0.08 $1.09, p=0.069$ ). Nineteen patients received less than 6 cycles of cisplatin and doxorubicin mainly because of grade 3 or 4 toxicities (11), disease progression (6), patient refusal (1), and physician choice (1). Conclusion: In our study, adult patients with localized highgrade osteosarcoma treated with chemotherapy without methotrexate had unfavorable outcomes. The cumulative doxorubicin dose and the number of cisplatin/doxorubicin cycles were associated with improved OS. The investigation of additional treatment strategies is of utmost importance to improve adult patients' outcomes.
\end{abstract}

Keywords: Osteosarcoma; Antineoplastic agents; Doxorubicin; Methotrexate.

\footnotetext{
1.Instituto Do Cancer Do Estado De Sao Paulo, Clinical Oncology - Sao Paulo - Sao Paulo - Brazil

Financial support: none to declare.

Conflicts of interest: The authors declare no conflict of interest relevant to this manuscript.

Correspondence author: Veridiana Pires de Camargo.

E-mail: veripcamarg067@gmail.com
} 


\section{RESUMO}

Introdução: O tratamento padrão para pacientes pediátricos com osteossarcoma localizado inclui metotrexato em altas doses (HDMTX) e taxas de cura superiores a $60 \%$ são observadas. No entanto, em pacientes adultos, o perfil de toxicidade limita o uso de HDMTX e o medicamento geralmente é excluído dos protocolos de quimioterapia para esse grupo. Nosso objetivo foi avaliar os resultados de pacientes adultos com osteossarcoma localizado tratados com quimioterapia sem metotrexato. Métodos: Nesta coorte retrospectiva, avaliamos pacientes adultos com osteossarcoma de alto grau que receberam tratamento quimioterápico sem metotrexato em um centro de referência de câncer de 2007 a 2018. Os resultados analisados foram sobrevida livre de recorrência (SLR), sobrevida global (SG) e fatores prognósticos associados à sobrevida global. Resultados: Um total de 48 pacientes apresentou doença localizada e recebeu tratamento com quimioterapia sem metotrexato. A maioria deles recebeu quimioterapia com uma combinação de cisplatina e doxorrubicina $(n=42,87,5 \%)$. A idade média foi de 27 anos (intervalo de 16,8-66,7). Com um acompanhamento médio de 29,2 meses, o RFS médio foi de 29,9 meses. SG mediano não foi alcançado. As taxas de SLR e SG em 5 anos foram de 35,1\% (IC 95\%: 20,3-50,2\%) e 71,6\% (IC 95\%: 52,3-84,2\%), respectivamente. Pacientes que receberam doses cumulativas de doxorrubicina $\geq 375 \mathrm{mg} / \mathrm{m} 2$ tiveram melhor SG do que aqueles que receberam doses mais baixas (HR 0,26, IC 95\%: 0,07-0,94, $p=0,041$ ). Da mesma forma, os pacientes que receberam $\geq 6$ ciclos de cisplatina neoadjuvante/adjuvante tenderam a ter melhor SG do que aqueles que receberam $<6$ ciclos (HR 0,30, IC 95\%: 0,08-1,09, $p=0,069$ ). Dezenove pacientes receberam menos de 6 ciclos de cisplatina e doxorrubicina principalmente por causa de toxicidades de grau 3 ou 4 (11), progressão da doença (6), recusa do paciente (1) e escolha do médico (1). Conclusão: Em nosso estudo, pacientes adultos com osteossarcoma de alto grau localizado tratados com quimioterapia sem metotrexato tiveram resultados desfavoráveis. A dose cumulativa de doxorrubicina e o número de ciclos de cisplatina/ doxorrubicina foram associados à melhora da SG. A investigação de estratégias de tratamento adicionais é de extrema importância para melhorar os resultados dos pacientes adultos.

Descritores: Osteosarcoma; Agentes antineoplásicos; Doxorrubicina; Metotrexato.

\section{INTRODUCTION}

Osteosarcoma is a rare disease in adults and is the most common primary bone malignancy in children and young adolescents. ${ }^{[1]}$ Most patients present localized disease ${ }^{[2,3]}$ and cure rates are around 60$70 \%$ in the pediatric population with contemporary treatment regimens. ${ }^{[2]}$ In a large Brazilian study published in 2013 with 390 non-metastatic pediatric and young adults osteosarcoma patients, the median 5-year overall survival and relapse-free survival rates were $59 \%$ and $48 \%$, respectively. This is the largest study with osteosarcoma patients in a developing country, better reflecting the reality of our cohort. ${ }^{[3]}$

In the pediatric population, localized osteosarcoma treatment consists of multi-agent chemotherapy with usually includes high doses of methotrexate, doxorubicin, and cisplatin..$^{[1,2]}$ However, in adults, several studies questioned the value of methotrexate, due to the greater risk of serious toxicities like nephrotoxicity, otoxicity, mucositis, hepatotoxicity, pulmonary toxicity, and neurotoxicity. As in other prospective studies, the impact of adding methotrexate to the chemotherapy regimen failed to demonstrate an increase in overall survival. ${ }^{[4-7]}$
Considering this, chemotherapy for adult patients with osteosarcoma has no standard. A comprehension of these patients' outcomes without methotrexate is essential to understand the disease scenario of this selected population and to guide the development of new treatment strategies with acceptable tolerance. The present study aimed to evaluate the outcomes of adult patients with high-grade localized osteosarcoma treated with chemotherapy regimens without methotrexate.

\section{METHODS}

\section{Study design and participants}

In this single-center retrospective cohort, adult patients with high-grade osteosarcoma who received treatment at a Brazilian tertiary public cancer center (Instituto do Câncer do Estado de São Paulo, Sao Paulo, Brazil) between 2007 and 2018 were evaluated. Electronic medical records were reviewed to collect patients' data, including clinical and demographical characteristics, treatment received, and outcomes.

Patients were included in the analysis if they presented with histologically confirmed localized high-grade osteosarcoma and received neoadjuvant, adjuvant, or perioperative treatment with a chemotherapy regimen 
that did not include methotrexate. Additionally, patients should be at least 16 years old. Exclusion criteria were the presence of distant metastasis, a localized disease not amenable to curative surgery at diagnosis, head and neck osteosarcoma, and diagnosis of a secondary malignant neoplasm in the past 5 years (except for nonmelanoma skin cancer).

Local ethics committees approved the present study.

\section{Treatment}

Systemic treatment consisted of neoadjuvant or adjuvant chemotherapy with regimens based on combinations of cisplatin, doxorubicin, ifosfamide, and/or etoposide. Perioperative chemotherapy with chemotherapy cycles both pre- and post-surgery was also acceptable. The timing of chemotherapy in relation to surgery was defined by physicians' discretion.

All patients had curative surgery planned as part of their oncologic treatment. The planned surgery was not performed only in case of patients' refusal, disease progression during neoadjuvant chemotherapy, or other complication that contraindicated surgery.

\section{Statistical analysis}

Patients and treatment characteristics were summarized using descriptive statistics. Median and range were used to summarize continuous variables. Categorical variables were presented using their absolute and relative frequencies.

The outcomes evaluated were overall survival (OS) and recurrence-free survival (RFS). OS was defined as the time from diagnosis until death from any cause. RFS was the time from diagnosis until disease recurrence or death, whichever occurred first. Patients without these events were censored at the time of last follow-up.

Survival analyses were performed using the KaplanMeier method, with the log-rank test to compare the difference between survival curves when appropriate. Factors associated with OS were investigated using univariate Cox proportional hazards model. Factors included in the univariate analysis were: age ( $\geq 40 \mathrm{y}$ vs. $<40 y$ ), ECOG-performance status ( $\geq 2$ vs. $0-1)$, Huvos criteria after neoadjuvant chemotherapy (3-4 vs. $1-2$ ), number of cisplatin cycles ( $\geq 6$ vs. $<6$ cycles), cumulative dose of doxorubicin $\left(\geq 375 \mathrm{mg} / \mathrm{m}^{2}\right.$ vs. $<375 \mathrm{mg} / \mathrm{m}^{2}$ ), the occurrence of grade 3-4 toxicities (yes vs. no), and type of surgery (amputation vs. preservation) The Huvos classification is a grading system from I-IV of the pathological response after chemotherapy, with higher grades being associated with better treatment response. ${ }^{[2]}$

For statistical significance, we considered p-valuesless than 0.05. Statistical analyses were performed using Stata software, version 15.1 (StataCorp, Texas, USA).

\section{RESULTS}

\section{Patients' characteristics}

A total of 97 adult patients with osteosarcoma were treated at ICESP from 2007 to 2018 . Sixty-one patients had localized resectable disease at diagnosis, and 48 of them (78.7\%) received neoadjuvant or adjuvant chemotherapy without methotrexate, composing the study population. The protocol consisted of cisplatin $60 \mathrm{mg} / \mathrm{m}^{2}$ day 1 and 2 with doxorubicin $37,5 \mathrm{mg} / \mathrm{m}^{2}$ day 1 and day 2 with filgrastim support from day 3 until day 12 .

Median age was 27 years (range 16.8-66.7) and the majority of patients (93.7\%) presented primary tumor site at extremities. The most common histologic subtype was osteoblastic (43.7\%). Patients' clinical and demographical characteristics are summarized in Table 1.

The chemotherapy regimen received by most of the patients was a combination of cisplatin and doxorubicin $(n=42 ; 87.5 \%)$. The other six patients received cisplatin, doxorubicin, ifosfamide, and etoposide $(n=6 ; 12.5 \%)$, an institutional study evaluating the role of adding ifosfamide and etoposide in the adjuvant treatment. The median number of cisplatin/doxorubicin cycles was 6 (range 3-8), and the median cumulative dose of doxorubicin was $375 \mathrm{mg} / \mathrm{m}^{2}$ (range $225-495 \mathrm{mg} / \mathrm{m}^{2}$ ).

The most common second-line and third-line treatments were ifosfamide and etoposide (22 patients) and gemcitabine and docetaxel (8 patients), respectively.

\section{Patients' outcomes}

Patients were followed for a median time of 29.2 months. During the follow-up period, 27 patients had disease recurrence or death. Median RFS was 29.9 months (95\% CI: 11.3-NR months). Five-year RFS rate was $35.1 \%(95 \% \mathrm{Cl}: 20.3-50.2 \%)$. Ten of the 48 patients died, with the median OS not reached. Fiveyear OS rate was $71.6 \%$ (95\% Cl: 52.3-84.2\%). KaplanMeier survival curves are shown in Figure 1.

In the univariate analysis, higher cumulative doses of doxorubicin $\left(\geq 375 \mathrm{mg} / \mathrm{m}^{2}\right)$ were associated with improved OS in comparison with lower doses $\left(<375 \mathrm{mg} / \mathrm{m}^{2}\right)$ (HR 0.26, 95\% Cl: 0.07-0.94, p=0.041). Patients who received a cumulative doxorubicin dose more or equal to $375 \mathrm{mg} / \mathrm{m}^{2}$ had a 5 -year OS rate of $79.5 \%$ compared to $45 \%$ among those who received lower doses ( $p$ log-rank=0.029). Another factor that tended to be associated with OS was the number of cisplatin/doxorubicin cycles (neoadjuvant and adjuvant) (HR 0.30, 95\% Cl: 0.08-1.09, $\mathrm{p}=0.069$ ). The results of the univariate analysis of factors associated with overall survival are presented in Table 2. Figure 2 shows the Kaplan-Meier curves for OS according to the cumulative dose of doxorubicin received.

The main reasons for receiving less than six cycles were grade 3-4 toxicities $(n=11 / 19,57.9 \%)$ and disease progression during chemotherapy $(n=6 / 19$, $31.6 \%)$. In the overall study population, 17 patients (35.4\%) had grade 3-4 toxicities. The most important grade 3-4 toxicities were hematologic, including neutropenia, asthenia, and gastrointestinal. 
Table 1. Patients' characteristics.

\begin{tabular}{|c|c|c|}
\hline & $\begin{array}{c}\text { No of } \\
\text { patients } \\
(n=48)\end{array}$ & $\%$ \\
\hline \multicolumn{3}{|l|}{ Age, years } \\
\hline Median (range) & $27(16.8-66.7)$ & \\
\hline \multicolumn{3}{|l|}{ Gender } \\
\hline Male & 28 & 58.3 \\
\hline Female & 20 & 41.7 \\
\hline \multicolumn{3}{|l|}{ ECOG-PS } \\
\hline 0 & 6 & 12.5 \\
\hline 1 & 29 & 60.4 \\
\hline 2 & 12 & 25 \\
\hline 3 & 1 & 2.1 \\
\hline \multicolumn{3}{|l|}{ Primary tumor site } \\
\hline Extremity & 45 & 93.7 \\
\hline Axial & 3 & 6.2 \\
\hline \multicolumn{3}{|l|}{ Initial TNM stage } \\
\hline 1 & 3 & 6.2 \\
\hline II & 34 & 70.8 \\
\hline III & 9 & 18.7 \\
\hline NA & 2 & 4.2 \\
\hline \multicolumn{3}{|l|}{ Histologic type } \\
\hline Osteoblastic & 21 & 43.7 \\
\hline Condroblastic & 4 & 8.3 \\
\hline Mixed & 8 & 16.7 \\
\hline Pleomorphic sarcoma & 3 & 6.2 \\
\hline Others & 10 & 20.8 \\
\hline NA & 2 & 4.2 \\
\hline \multicolumn{3}{|l|}{ Chemotherapy timing } \\
\hline Neoadjuvant & 10 & 20.8 \\
\hline Adjuvant & 10 & 20.8 \\
\hline $\begin{array}{l}\text { Perioperative } \\
\text { (neoadjuvant }+ \text { adjuvant) }\end{array}$ & 28 & 58.4 \\
\hline \multicolumn{3}{|l|}{ Huvos* } \\
\hline 1 & 15 & 39.5 \\
\hline II & 9 & 23.6 \\
\hline III & 7 & 18.4 \\
\hline IV & 1 & 2.6 \\
\hline NA & 6 & 15.8 \\
\hline \multicolumn{3}{|l|}{ Surgery type } \\
\hline Limb preservation & 29 & 60.4 \\
\hline Amputation & 19 & 39.6 \\
\hline
\end{tabular}

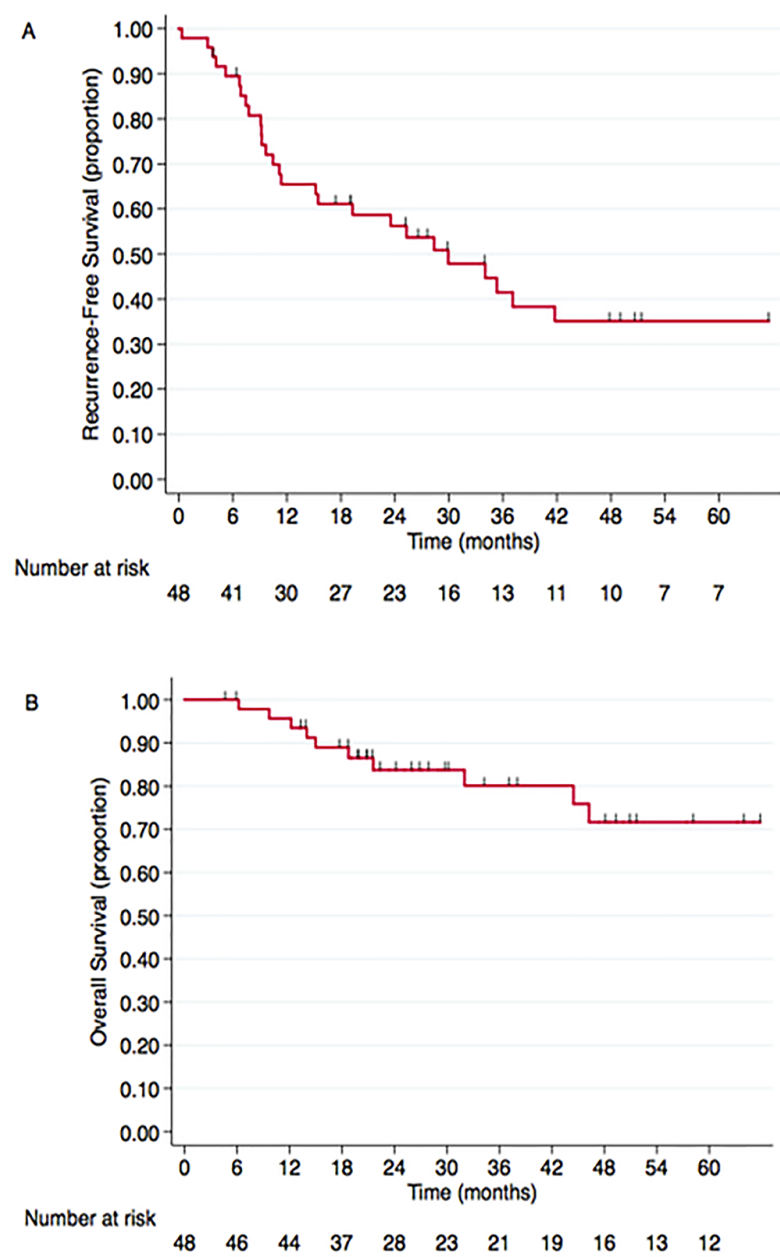

Figure 1. A. Kaplan-Meier curves for recurrencefree survival; B. Overall survival. Of adult patients with localized high-grade osteosarcoma treated with chemotherapy without methotrexate.

Table 2. Factors associated with overall survival (Cox proportional hazards model).

\begin{tabular}{lcc}
\hline Variable & HR $(95 \%$ Cl) & p-value \\
\hline Age ( $\geq 40 y$ vs. < 40y) & $1.01(0.21-4.81)$ & 0.980 \\
ECOG-PS ( $\geq 2$ vs. 0-1) & $0.76(0.16-3.61)$ & 0.732 \\
Huvos (3-4 vs. 1-2) & $1.44(0.27-7.54)$ & 0.661 \\
$\begin{array}{l}\text { No. of CT cycles } \\
\text { ( } \geq 6 \text { vs. }<6 \text { cycles) }\end{array}$ & $0.30(0.08-1.09)$ & 0.069 \\
$\begin{array}{l}\text { Cumulative } \\
\text { doxorubicin dose } \\
\text { ( } \geq 375 \text { vs. <375mg/m2) }\end{array}$ & $0.26(0.07-0.94)$ & 0.041 \\
$\begin{array}{l}\text { Grade 3-4 toxicities } \\
\text { (yes vs. no) }\end{array}$ & $1.37(0.38-4.88)$ & 0.627 \\
$\begin{array}{l}\text { Type of surgery } \\
\text { (amputation vs } \\
\text { preservation) }\end{array}$ & $2.30(0.64-8.2)$ & 0.198 \\
\hline $\begin{array}{l}\text { HR: Hazard ratio; Cl: Confidence interval; No: Number; CT: } \\
\text { Chemotherapy. }\end{array}$ &
\end{tabular}




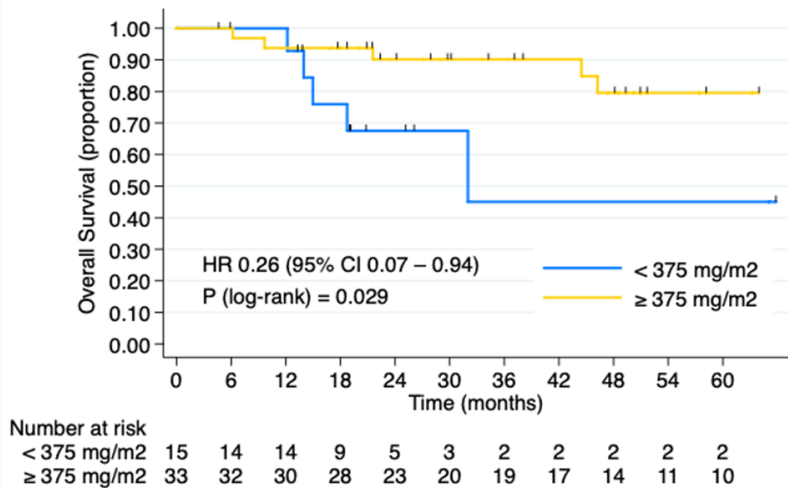

Figure 2. Kaplan-Meier curves for overall survival of adult patients with localized high-grade osteosarcoma treated with chemotherapy without methotrexate, according to cumulative dose of doxorubicin received (neoadjuvant, adjuvant or perioperative).

\section{DISCUSSION}

In the present study, adult patients with localized osteosarcoma treated with chemotherapy regimens without high-dose methotrexate had unfavorable outcomes, with only $35 \%$ disease-free and $71.5 \%$ alive in 5 years. The only factor associated with overall survival was the chemotherapy dose received, with a cumulative doxorubicin dose greater than $375 \mathrm{mg} /$ $\mathrm{m}^{2}$ and the number of cisplatin/doxorubicin cycles greater than 6 . Similarly, in the non-metastatic cohort of the largest Brazilian pediatric study with a median follow up of 92 months, the 5-year overall survival and relapse-free survival rates were 59\% and 48\%, respectively. ${ }^{[3]}$ The most important factors associated with survival were metastases at diagnosis, grade of necrosis, and type of surgery. Both cohorts included patients with locally advanced disease at diagnosis with amputation rates around $40 \%$ in both cohorts, probably related to the difficulty for these patients to reach a specialized sarcoma center in Brazil. ${ }^{[3]}$

In a study by Souhami et al. (1997), ${ }^{[4]} 407$ patients with non-metastatic osteosarcoma were randomized to receive cisplatin and doxorubicin or vincristine, highdose methotrexate, and doxorubicin in the preoperative setting or bleomycin, cyclophosphamide, actinomycin D, vincristine, high-dose methotrexate, doxorubicin, and cisplatin in the postoperative setting. ${ }^{[3]}$ Only $51 \%$ of patients could complete treatment with multiple drugs versus $94 \%$ with the two-drug regimen. The percentage of patients with tumor necrosis greater than $90 \%$ was $29 \%$ in both groups. In addition, the 5-year overall survival rate was $55 \%$ in both. This study was criticized for the low overall survival in the high-dose methotrexate group, compared to the previous studies. ${ }^{[4]}$ In another randomized study, the addition of methotrexate to cisplatin and doxorubicin regimen resulted in lower disease-free survival (DFS) (5-year DRS rate: $57 \%$ versus $41 \%, p=0.02$ ) and overall survival (5-year OS rate: $64 \%$ versus $50 \%, p=0.10) .{ }^{[4]}$ In a subgroup of patients with necrosis greater than $90 \%(n=66)$, better progressionfree and overall survival were observed. ${ }^{[5]}$

Another recent study by Wippel B et al. (2019) [6] evaluated 33 pediatric and adult patients with localized osteosarcoma submitted to high-dose methotrexate $\left(12 \mathrm{~g} / \mathrm{m}^{2}\right)$ with cisplatin and doxorubicin. They found a statistically significant delay in clearance of methotrexate (120 vs. 79 hours, $p<0.001$ ) as well as a lower number of cycles in the adult patients (12 vs. 5 cycles, $p<0.01$ ). The authors explained that subsequent delays in doxorubicin/cisplatin therapy due to slow methotrexate clearance may arguably negatively impact disease outcomes and may play a role in physician decision-making process. ${ }^{[6]}$ The histologic response is a well-established prognostic indicator in osteosarcoma, and, in this study, the histologic response was positively correlated with the number of preoperative high-dose methotrexate doses received. A trend toward improved survival was noted for patients who received at least seven doses of high-dose methotrexate. ${ }^{[6]}$ However, in our study, we found that the number of cisplatin and doxorubicin cycles correlated with outcome.

Besides, a recent Brazilian study from our group performed a retrospective study of 10 patients aged $16-23$ years who received high-dose methotrexate. Two of them died of therapy-related causes. ${ }^{[7]}$ The EUROpean Bone Over 40 Sarcoma Study (EURO-BOSS) prospectively gathered data on high-grade osteosarcoma patients ages 41-65, an older population than studied here. EURO-BOSS patients received investigator's choice therapy and included 48 patients who received highdose methotrexate. Among these older patients, 23\% experienced delayed methotrexate clearance and only one developed $\geq$ grade 2 nephrotoxicity. ${ }^{\left[{ }^{8]}\right.}$

In our center, the clearance delay of methotrexate, the high toxicity in the adult population, and the loss of dose intensity of cisplatin and doxorubicin contributed to exclude the drug from our treatment protocol in adult osteosarcoma. In face of this, another treatment strategy we studied was the addition of ifosfamide and etoposide to the adjuvant treatment. We included six patients in a phase II study evaluating the addition of 6 cycles of ifosfamide and etoposide (IE) after surgery for patients who have already received up to 6 cycles of cisplatin and doxorubicin preoperatively. ${ }^{[9]}$ We compared this group to another six matched patients that received 3 cycles of cisplatin and doxorubicin (standard group) before and after surgery. Median age was 20.1 years. Grade $\geq 3$ toxicities occurred in $83 \%$ of the IE group, including one grade 5 toxicity. The study was interrupted because of the alarming toxicity. In addition, numerally lower recurrence-free survival (median: 11.3 vs. 31.8 months; HR 1.68, 95\% Cl: $0.36-$ 7.89) and overall survival rates (median: 44.4 vs. 51.2 months; HR 1.57, 95\% Cl: 0.29-8.46) were observed in IE group. ${ }^{[9]}$ Thus, additional treatment strategies are still warranted to improve adult patients' outcomes.

Our study's most important limitations include the small number of patients, the single-center, and the retrospective nature. Adult osteosarcoma remains a challenging disease with most treatments based on pediatric studies. In the present study, patients with localized osteosarcoma treated with chemotherapy without methotrexate at a public reference cancer center in Brazil had unfavorable outcomes compared 
to the worldwide pediatric population but similar to the Brazilian pediatric population. In developing countries, patients arrive to reference centers with locally advanced disease, which justifies the bad outcomes in both pediatric and adult populations. However, our institution is a reference center, and publishing articles and reviewing the literature on rare diseases is of utmost importance to help develop treatment guidelines in a developing country like Brazil.

\section{CONCLUSION}

In conclusion, the use of high-dose methotrexate $\left(12 \mathrm{~g} / \mathrm{m}^{2}\right)$ remains controversial in adult osteosarcoma and, in our opinion, should be used only inside clinical trial protocols. The clearance delay of methotrexate may contribute to postponing the subsequent cycles of the main drugs cisplatin and doxorubicin, interfering directly in the outcome. Our study found that the number of cisplatin and doxorubicin cycles and the cumulative doxorubicin dose were associated with better survival. However, $35 \%$ of the patients had a dose reduction because of grade 3 or 4 toxicity even without methotrexate. The most important guidelines like NCCN and ESMO guidelines still include methotrexate in the treatment of osteosarcoma in patients with less than 40 years old inside reference centers to manage the subsequent toxicities correctly. ${ }^{[10,11]}$ We definitively need more multi-institutional studies to elaborate an adult osteosarcoma guideline.

\section{REFERENCES}

1. Widemann BC, Balis FM, Kempf-Bielack B, Bielack S, Pratt $C B$, Ferrari $S$, et al. High-dose methotrexate-induced nephrotoxicity in patients with osteosarcoma. Cancer. 2004 May;100(10):2222-32.

2. Huvos AG, Rosen G, Marcove RC. Primary osteogenic sarcoma: pathologic aspects in 20 patients after treatment with chemotherapy en bloc resection, and prosthetic bone replacement. Arch Pathol Lab Med. 1977 Jan;101(1):14-8.
3. Petrilli AS, Brunetto AL, Cypriano MS, Ferraro AA, Macedo CRPD, Senerchia AA, et al. Fifteen years' experience of the Brazilian Osteosarcoma Treatment Group (BOTG): a contribution from an emerging country. J Adolesc Young Adult Oncol. 2013 Dec;2(4):145-52.

4. Souhami RL, Craft AW, Van Der Eijken JW, Nooij M, Spooner D, Bramwell VH, et al. Randomised trial of two regimens of chemotherapy in operable osteosarcoma: a study of the European Osteosarcoma Intergroup. Lancet. 1997 Sep;350(9082):911-7.

5. Bramwell VH, Burgers $M$, Sneath $R$, Souhami $R$, Van Oosterom AT, Voûte PA, et al. A comparison of two short intensive adjuvant chemotherapy regimens in operable osteosarcoma of limbs in children and young adults: the first study of the European Osteosarcoma Intergroup. J Clin Oncol. 1992 Oct;10(10):1579-91.

6. Wippel B, Gundle KR, Dang T, Paxton J, Bubalo J, Stork $L$, et al. Safety and efficacy of high-dose methotrexate for osteosarcoma in adolescents compared with young adults. Cancer Med. 2019 Jan;8(1):111-6.

7. Negrão MV, Rocha LSS, Girardi DM, Feher O. Perioperative chemotherapy with and without high-dose methotrexate in adult osteosarcoma. Anticancer Drugs. 2017 Sep;28(8):915-21.

8. Ferrari S, Bielack SS, Smeland S, Longhi A, Egerer G, Hall KS, et al. EURO-B.O.S.S.: a European study on chemotherapy in bone-sarcoma patients aged over 40: outcome in primary high-grade osteosarcoma. Tumori. 2018 Jan/Feb;104(1):30-6.

9. Bonadio R, Silva M, Matos G, Camargo V. Addition of ifosfamide and etoposide to standard chemotherapy for adult patients with localized osteosarcoma: a matchedcohort study. In: II Semana Brasileira de Oncologia XXI Congresso Brasileiro de Oncologia Clínica; 23-26 Oct 2019; Rio de Janeiro, Brazil. Rio de Janeiro (RJ): Sociedade Brasileira de Oncologia Clínica (SBOC); 2019.

10. National Comprehensive Cancer Network (NCCN). Clinical practice guidelines in oncology. Bone Cancer. Plymouth Meeting: NCCN; 2020.

11. Casali PG, Bielack S, Abecassis N, Aro HT, Bauer S, Biagin $\mathrm{R}$, et al. Bone sarcomas: ESMO-PaedCan-EURACAN clinical practice guidelines for diagnosis, treatment and followup. Ann Oncol. 2018 Oct;29(Suppl 4):iv79-iv95. 